\title{
AWM Institutes New Research Prizes for Early-Career Women
}

Ruth Charney

Here is your quiz for today: Name five women who have won major prizes for their mathematics research. Having trouble? That's not surprising. A recent study [1] by the Association for Women in Science (AWIS) shows that, in most scientific disciplines, the number of women receiving prizes for research is not consistent with the representation of women in the research community. There are multiple plausible explanations for this imbalance, and a variety of approaches have been proposed for addressing the issue. Clearly, one key strategy is to increase the pool of women considered for such prizes.

The Association for Women in Mathematics (AWM) is pleased to announce a new series of research prizes. These prizes will focus on women at the beginning stages of their careers. Early-career prizes (such as the AMS Centennial Fellowship) can significantly affect the career trajectory of recipients. Receiving such a prize may lead to promotions, job offers, speaking invitations, and new collaborations. In addition, prizes beget prizes. Highlighting outstanding work by young women increases their chances of being nominated for major prizes in the future. Thus, the new AWM prizes will serve both to celebrate the increasing contributions of women to mathematical research and to identify potential nominees for future prizes. The prize recipients will also provide inspiring role models for the next generation of women mathematicians.

The goal of this initiative is to institute four new research prizes. They will be organized by field, with four broadly defined areas: analysis,

Ruth Charney is president-elect of the Association for Women in Mathematics and professor of mathematics at Brandeis University. Her email address is charney@ brandeis. edu.

DOI: http://dx.doi.org/10.1090/noti939 algebra/number theory, geometry/topology, and applied mathematics. Two of the four prizes will be awarded each year, with each topic appearing in alternate years. The awards will be aimed at early-career women, generally pretenure or within ten years of receiving their Ph.D. The first two of these prizes, the AWM-Sadosky Research Prize in Analysis and the AWM-Microsoft Research Prize in Algebra and Number Theory, have been funded, and the inaugural awards for these two prizes will take place at the Joint Mathematics Meetings in Baltimore, Maryland, in January 2014.

The AWM-Sadosky Research Prize in Analysis is named for Cora Sadosky (1940-2010), a former president of AWM. It is made possible by generous contributions from Cora's husband, Daniel J. Goldstein; daughter, Cora Sol Goldstein; and friends Judy and Paul S. Green. Sadosky was president of AWM from 1993 to 1995 and a long-time faculty member at Howard University. Born in Argentina in 1940, she received her doctoral degree in mathematics from the University of Chicago in 1965 and wrote over fifty papers in harmonic analysis and operator theory. A strong advocate for women in mathematics and active in promoting the greater participation of African-Americans in mathematics, Sadosky served as a member of the Human Rights Advisory Committee of the Mathematical Sciences Research Institute as well as the AMS Committee on Human Rights. She was also a member-at-large of the AMS Council (1995-1998) and served on two of the main policy committees of the AMS: the Committee on Science Policy (1996-1998) and the Committee on the Profession (1995-1996).

As described by Daniel and Cora Sol Goldstein and Judy Green, "Cora loved mathematics and hated discrimination. She saw mathematics as an object of supreme beauty and empowerment and was passionately committed to ensuring that everyone in society would have total access to 
mathematics. Cora believed firmly in equality and freedom, and while she often spoke specifically of 'the right of women to mathematics,' she fought with intelligence and perseverance to increase the opportunities and possibilities in mathematics for all people." AWM is proud to honor her memory through this new prize.

The AWM-Microsoft Research Prize in Algebra and Number Theory is made possible by a generous contribution from Microsoft Research through the efforts of Kristin Lauter, a principal researcher and head of the Cryptography Research Group at Microsoft Research. Lauter is a cofounder of the Women in Numbers Network, a research collaboration community for women in number theory. She received an AWM mentoring grant in 1999 to work with Jean-Pierre Serre at the Collège de France and was the 2008 recipient of the Selfridge Prize in Computational Number Theory. She currently serves on the AWM Executive Committee.

Lauter observed, "The high-tech industry has started to funnel significant resources to promote the advancement of women in science, recognizing that achieving gender parity in science is a national priority and is crucial for the future success of the industry. The AWM Research Prizes are an exciting way to recognize the work of young female researchers in mathematics, focus attention on their contributions, and encourage the next generation of research leaders. This type of recognition can be important to ensuring future success in their careers, both in being awarded tenure and in securing grants to support ongoing research. It is also important to help create positive role models for younger women considering a research career in mathematics." AWM is grateful to Kristin Lauter and Microsoft Research for the opportunity to create this prize.

These new prizes for early-career mathematicians complement AWM's existing prizes, which recognize the achievements of women in mathematics at many levels as well as efforts to encourage young women to enter the field. The following awards are presented annually.

- The Alice T. Schafer Prize, named after one of the original founders of AWM, recognizes an undergraduate who has demonstrated excellence in mathematics.

- The Gweneth Humphreys Award recognizes a mathematics teacher (female or male) who has encouraged female undergraduate students to pursue mathematical careers or the study of mathematics at the graduate level.

- The Louise Hay Award recognizes outstanding achievements in any area of mathematics education.
- The Ruth I. Michler Memorial Prize provides a fellowship for a recently tenured woman to spend a semester focusing on her research at Cornell University.

Three other AWM awards are associated with annual lecture series.

- The Noether Lecture honors women who have made fundamental and sustained contributions to the mathematical sciences. These lectures are presented at the Joint Mathematics Meetings each January.

- The Sonia Kovalevsky Lecture highlights significant contributions of women to applied or computational mathematics. It is awarded jointly by AWM and the Society for Industrial and Applied Mathematics (SIAM), and the lecture is given at the SIAM Annual Meeting.

- The Etta Z. Falconer Lecture, established in memory of Falconer's profound vision and accomplishments in enhancing the movement of minorities and women into scientific careers, honors women who have made distinguished contributions to the mathematical sciences or mathematics education. It is awarded jointly by AWM and the Mathematical Association of America (MAA), and the lecture is presented at MathFest each summer.

AWM is excited to add the two new prizes discussed above to this list.

So here is your next quiz question: Name five women who have the potential to win major prizes in the future. Are any of them eligible for the Sadosky Prize in Analysis or the Microsoft Prize in Algebra and Number Theory? AWM welcomes nominations for these prizes. The deadline for nominations for both prizes is February 15, 2013. Please visit www . awm-math. org for more details.

Inquiries about funding the remaining two prizes in geometry/topology and applied mathematics are also welcome! Please see https:// sites.goog7e.com/site/awmmath/home/ announcements/awmresearchprizes.

\section{References}

[1] AWIS AWARDS (Advancing Ways of Awarding Recognition in Disciplinary Societies) Project, Recognition of Women in Science, Technology, Engineering and Mathematics (STEM), http://www.awis.org/displaycommon. cfm?an=1\&subarticlenbr=397. 